\title{
International evidence-based guidelines on Point of Care Ultrasound (POCUS) for critically ill neonates and children issued by the POCUS Working Group of the European Society of Paediatric and Neonatal Intensive Care (ESPNIC)
}

Yogen Singh ${ }^{1,2^{*+}} \mathbb{D}$, Cecile Tissot ${ }^{3 \dagger}$, María V. Fraga ${ }^{4}$, Nadya Yousef $^{5}$, Rafael Gonzalez Cortes ${ }^{6}$, Jorge Lopez ${ }^{6}$, Joan Sanchez-de-Toledo ${ }^{7}$, Joe Brierley ${ }^{8}$, Juan Mayordomo Colunga ${ }^{9}$, Dusan Raffaj ${ }^{10}$, Eduardo Da Cruz ${ }^{11}$, Philippe Durand ${ }^{12}$, Peter Kenderessy ${ }^{13}$, Hans-Joerg Lang ${ }^{14}$, Akira Nishisaki ${ }^{15}$, Martin C. Kneyber ${ }^{16}$, Pierre Tissieres $^{12}$, Thomas W. Conlon ${ }^{15}$ and Daniele De Luca ${ }^{5,17}$

\begin{abstract}
Background: Point-of-care ultrasound (POCUS) is nowadays an essential tool in critical care. Its role seems more important in neonates and children where other monitoring techniques may be unavailable. POCUS Working Group of the European Society of Paediatric and Neonatal Intensive Care (ESPNIC) aimed to provide evidence-based clinical guidelines for the use of POCUS in critically ill neonates and children.

Methods: Creation of an international Euro-American panel of paediatric and neonatal intensivists expert in POCUS and systematic review of relevant literature. A literature search was performed, and the level of evidence was assessed according to a GRADE method. Recommendations were developed through discussions managed following a Quaker-based consensus technique and evaluating appropriateness using a modified blind RAND/UCLA voting method. AGREE statement was followed to prepare this document.

Results: Panellists agreed on 39 out of 41 recommendations for the use of cardiac, lung, vascular, cerebral and abdominal POCUS in critically ill neonates and children. Recommendations were mostly (28 out of 39) based on moderate quality of evidence ( $\mathrm{B}$ and $\mathrm{C}$ ).

Conclusions: Evidence-based guidelines for the use of POCUS in critically ill neonates and children are now available. They will be useful to optimise the use of POCUS, training programs and further research, which are urgently needed given the weak quality of evidence available.
\end{abstract}

Keywords: Neonate, Children, Ultrasound, Point of care ultrasound (POCUS), Paediatric intensive care unit (PICU), Neonatal intensive care unit (NICU)

\footnotetext{
* Correspondence: Yogen.Singh@nhs.net

Yogen Singh and Cecile Tissot equally contributed and shall be considered as first authors

'Department of Paediatrics - Neonatology and Paediatric Cardiology,

Cambridge University Hospitals and University of Cambridge School of

Clinical Medicine, Biomedical Campus, Hills Road, Cambridge CB2 0QQ, UK

${ }^{2}$ Addenbrooke's Hospital, Box 402, Cambridge, UK

Full list of author information is available at the end of the article
}

(c) The Author(s). 2020 Open Access This article is distributed under the terms of the Creative Commons Attribution 4.0 International License (http://creativecommons.org/licenses/by/4.0/), which permits unrestricted use, distribution, and reproduction in any medium, provided you give appropriate credit to the original author(s) and the source, provide a link to the Creative Commons license, and indicate if changes were made. The Creative Commons Public Domain Dedication waiver (http://creativecommons.org/publicdomain/zero/1.0/) applies to the data made available in this article, unless otherwise stated. 


\section{Introduction}

The incorporation of Point of Care Ultrasound (POCUS) has represented a transformative change in clinical practice, challenging the traditional diagnostic and procedural "art" of medicine, especially in acute care environments. It has emerged as "the new" clinical tool and it has displaced, in some way, the classical stethoscope. It is performed and interpreted by the bedside clinician with the intent of either answering a focused question or achieving a specific procedural goal.

The use of POCUS by critical care providers has increased significantly in recent years and adult emergency medicine had pioneered this field with the publication of guidelines for implementation of structured POCUS training [1-7]. These efforts were translated into paediatrics through emergency medicine. Since then, POCUS has gained popularity and expanded across many paediatric disciplines. However, unified guidelines on the use of POCUS and training do not exist yet for the paediatric and neonatal critical care.

Bedside goal-directed echocardiography has been the first POCUS application in paediatric practice with guidelines for implementation. An expert statement was published in 2011, followed by the United Kingdom Expert Consensus Statement on Neonatologist Performed Echocardiography (NPE) and recommendations for NPE in Europe [8-10]. The Australian Clinician Performed Ultrasound (CPU) programme is a well-established academic curriculum developed to train neonatologists in the use of POCUS, though applications are limited to the evaluation of the neonatal brain and heart $[10,11]$ and the training programme is restricted to neonatal physiology. Non-cardiac POCUS may carry more opportunities for use as well as a number of benefits for both patients and providers. However, the lack of guidelines is a barrier to widespread adoption.

As more acute care providers invest in POCUS technology, it is critically important to define POCUS main purposes, establish formal training and develop accreditation guidelines, in order to maximise POCUS benefits and reducing risks.

Therefore, the European Society for Paediatric and Neonatal Intensive Care (ESPNIC) assembled a group of international paediatric POCUS key opinion leaders to create evidence-based guidelines for the use of current and emerging POCUS applications in the neonatal (NICU) and paediatric intensive care units (PICU) by any clinician working in these units.

\section{Methods}

Three lead authors, one neonatologist (YS), one paediatric intensivist (DDL) and one paediatric cardiologist (CT), identified expert colleagues who significantly contributed with publications in the POCUS field and/or have developed POCUS training courses in the last 10 years, similarly to what had been done with previous ESPNIC guidelines [12]. Panellists selection was performed prior to the literature search and for logistic reasons, the number of participants was limited to a maximum of 20. These colleagues should have been fairly representative of all POCUS fields and both Europe and North America and include also non-ESPNIC members. Moreover, at least one co-author should have been an expert in guidelines development and supervised the whole methodology, while literature search was performed by each panellist for their sub-section. All invited experts agreed to participate. Details of the methods used to produce these guidelines are given in the additional file for online supplementary material (see Additional file 1). These guidelines followed relevant ESPNIC internal procedures for manuscript endorsement, and this included an external review by ESPNIC officers not included among the panellists. Guidelines have been prepared according to the international Appraisal of Guidelines, Research and Evaluation (AGREE) [13]. Each recommendation is intended to be applied both for paediatric and neonatal patients, unless otherwise specified.

\section{Results}

A total of 41 recommendations on the use of POCUS in neonatal and paediatric critical care were discussed. There was strong agreement on 22 recommendations after first-round voting. Following the discussion in an in-person meeting among the experts (organised within the 2018 ESPNIC congress (Paris, France)), 19 recommendations were re-worded and re-voted in the second round (Fig. 1). There was agreement on 17 recommendations and disagreement on 2 recommendations as summarised in Table 1 and discussed below.

A. Recommendations for use of cardiac POCUS

1. POCUS should not be used as a screening tool for diagnosing congenital heart defects in neonates and children, unless neonatologists/ paediatric intensivists have received an advanced echocardiography training specifically for this purpose-strong agreement (quality of evidence $A$ ). The goal of cardiac POCUS is to obtain physiological and haemodynamic information to aid in clinical decision making. If any structural abnormality are suspected or diagnosed while performing cardiac POCUS, a formal echocardiogram should be performed by a paediatric cardiologist $[8-11,14]$. POCUS should not be used as a screening tool for diagnosing congenital heart defects, unless neonatologists/paediatric intensivists have 


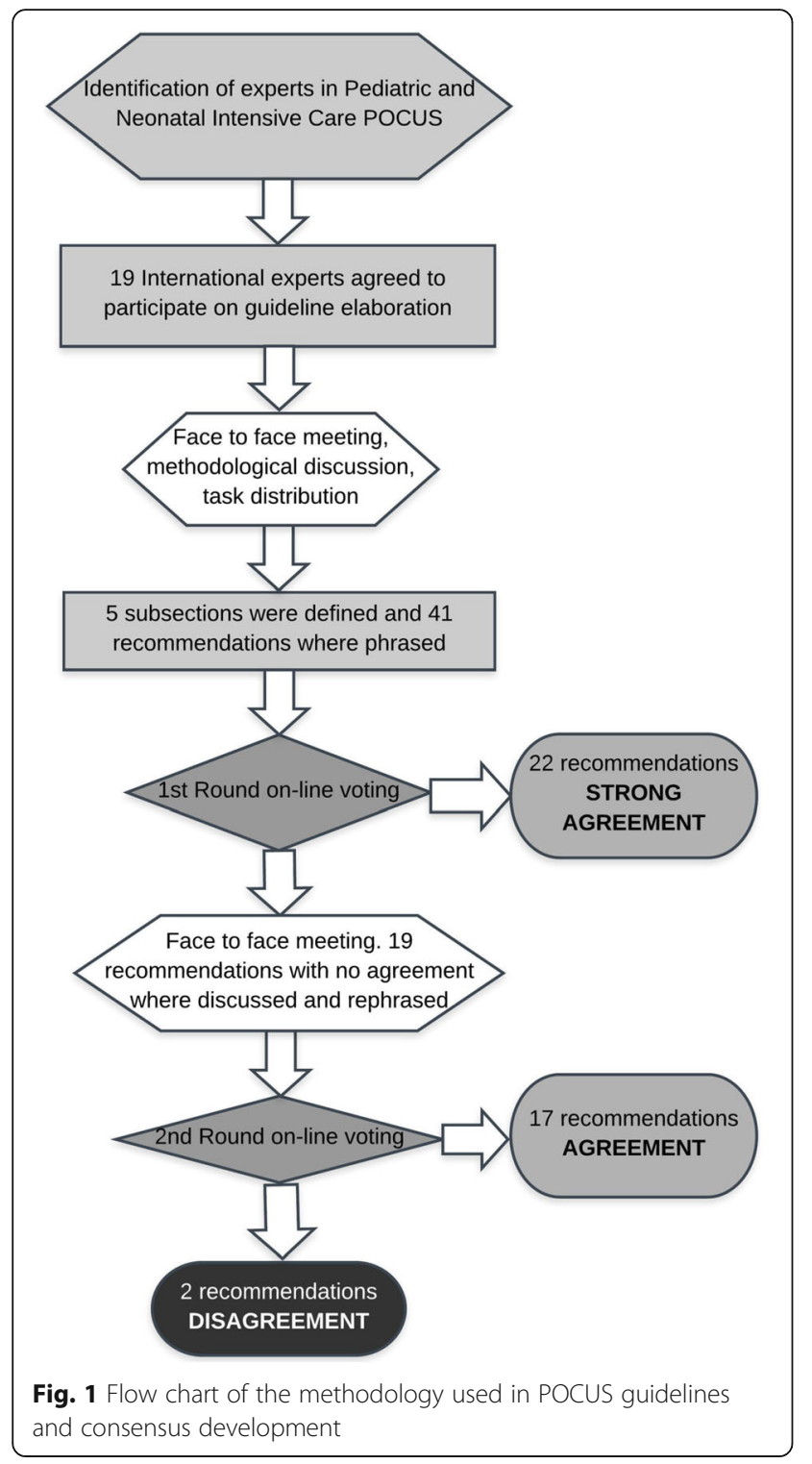

received an advanced echocardiography training specifically for this purpose.

2. POCUS may be helpful to assess cardiac filling (preload assessment) and intravascular volume status in neonates and children-strong agreement (quality of evidence D). Cardiac filling may be qualitatively assessed in apical windows and semi-quantitatively assessed by interrogating inferior vena-cava (IVC) size and variation during the cardiorespiratory cycle. During this evaluation, the eventual presence of right heart failure or elevated intra-abdominal pressure should be taken into consideration. In nonventilated adults and children with normal right atrial pressure, IVC collapse during inspiration is $>50 \%$. A dilated IVC with decreased collapsibility $(<50 \%)$ is a sign of increased right atrial pressure (above $10 \mathrm{mmHg}$ ) [15-17]. Conversely, a collapsed IVC may be suggestive of hypovolemia. Clinicians performing POCUS should be aware of its limitations especially in children on mechanical ventilation and neonates (especially when an umbilical central venous catheter is placed) in whom no validated normative data yet exist $[18,19]$. Moreover, mechanical ventilation (especially with high mean airway pressure), spontaneous breathing effort and some concomitant conditions may reduce the reliability of IVC evaluation to predict fluid responsiveness [20].

3. POCUS may be helpful to assess fluid responsiveness in neonates and children-strong agreement (quality of evidence D). The variation of velocity-time integrals (VTIs) measured at the left ventricular outflow tract (LVOT), using pulse wave Doppler (PWD) in apical 5-chamber view, during inspiration and expiration has been reported to predict volume responsiveness. A variation of $>15 \%$ has been reported to have a high predictive value with a sensitivity and specificity exceeding $90 \%$ [21, 22]. This has been validated in several studies, including many studies involving mechanically ventilated children [16, 23-31]. Accurate measurement of VTI needs acquisition of apical 5-chamber view and good alignment of ultrasound beam with the across LVOT like any other Doppler assessment, which requires advanced ultrasonography skills. Hence this recommendation is particularly for neonatal/paediatric intensivists with advanced POCUS skills.

4. POCUS may be helpful for qualitative assessment of cardiac function on visual inspection in neonates and children-strong agreement (quality of evidence D). POCUS should be used for qualitative assessment of cardiac contractility ("eyeballing" assessment) in multiple views such as apical 4-chamber (A4C), parasternal long (PLAX) and short-axis (PSAX) and sub-costal short-axis views $[8,15]$. Subcostal views may be very helpful in patients where parasternal or apical views impossible or sub-optimal, and in younger children or neonates where sub-costal views may provide even better image quality.

5. POCUS is helpful for semi-quantitative assessment of cardiac function in neonates and children [however, a detailed functional assessment should be performed by a person with advanced echocardiography training] - agreement (quality 
Table 1 Summary of recommendations on the use of POCUS in the neonatal and paediatric critical care

No. Recommendation

1. POCUS should not be used as a screening tool for diagnosing congenital heart defects in neonates and children, unless neonatologists/paediatric intensivists have received an advanced echocardiography training specifically for this purpose

2. POCUS may be helpful to assess cardiac filling (preload assessment) and intravascular volume status in neonates and children

3. POCUS may be helpful to assess fluid responsiveness in neonates and children

4. POCUS may be helpful for qualitative assessment of cardiac function on visual inspection in neonates and children

5. POCUS is helpful for semi-quantitative assessment of cardiac function in neonates and children [however, a detailed functional assessment should be performed by a person with advanced echocardiography training]

6. POCUS is helpful for assessment of pulmonary artery systolic pressure in pulmonary hypertension in neonates and children

\begin{tabular}{|c|c|}
\hline $\begin{array}{l}\text { Level of } \\
\text { agreement }\end{array}$ & $\begin{array}{l}\text { Quality of } \\
\text { evidence }\end{array}$ \\
\hline $\begin{array}{l}\text { Strong } \\
\text { agreement }\end{array}$ & $A$ \\
\hline $\begin{array}{l}\text { Strong } \\
\text { agreement }\end{array}$ & $D$ \\
\hline $\begin{array}{l}\text { Strong } \\
\text { agreement }\end{array}$ & D \\
\hline $\begin{array}{l}\text { Strong } \\
\text { agreement }\end{array}$ & $D$ \\
\hline Agreement & $C$ \\
\hline $\begin{array}{l}\text { Strong } \\
\text { agreement }\end{array}$ & B \\
\hline $\begin{array}{l}\text { Strong } \\
\text { agreement }\end{array}$ & B \\
\hline $\begin{array}{l}\text { Strong } \\
\text { agreement }\end{array}$ & $B$ \\
\hline $\begin{array}{l}\text { Strong } \\
\text { agreement }\end{array}$ & B \\
\hline $\begin{array}{l}\text { Strong } \\
\text { agreement }\end{array}$ & A \\
\hline
\end{tabular}

11. POCUS may be used to detect vegetation to make or exclude the diagnosis of endocarditis [however, a definitive diagnosis requires a detailed assessment by a paediatric cardiologist].

12. POCUS is helpful to distinguish between respiratory distress syndrome (RDS) and transient tachypnoea of the neonate (TTN)

13. POCUS is helpful to detect pneumonia in neonates and children

14. POCUS is helpful to semi-quantitatively evaluate lung aeration and help the management of respiratory intervention in acute respiratory distress syndrome (ARDS) in neonates and children

15. POCUS is helpful to recognise meconium aspiration syndrome (MAS)

16. POCUS is helpful for descriptive purposes in viral bronchiolitis but cannot provide a differential aetiological diagnosis

17. POCUS is helpful to accurately detect pneumothorax in neonates and children

18. POCUS is helpful to insert chest tube or perform needle aspiration in neonatal tension pneumothorax

19. POCUS is helpful to detect pleural effusions in neonates and children

20. POCUS is helpful to guide thoracentesis in neonates and children

21. POCUS is helpful to evaluate lung oedema in neonates and children

22. POCUS is helpful in detecting anaesthesia-induced atelectasis in neonates and children

23. POCUS-guided technique should be used for internal jugular vein (IJV) line placement in neonates and children

24. POCUS-guided technique is helpful for subclavian vein line placement in neonates and children

25. POCUS-guided technique is helpful for femoral line placement in neonates and children

26. POCUS-guided technique is helpful for arterial catheters placement in children

27. POCUS-guided technique is helpful for peripherally inserted central catheters in children

28. POCUS is helpful to locate catheter tip position in neonates and children

29. POCUS is helpful to detect cerebral blood flow changes in neonates and children

Disagreement D

Agreement B

Agreement B

Agreement B

Agreement C

Strong

agreement

Strong

agreement

Strong

agreement

Strong

agreement

Strong

agreement

Agreement C

Agreement C

Strong

agreement

Strong

agreement

Strong

agreement

Agreement B

Agreement B

Strong

agreement

Agreement B 
Table 1 Summary of recommendations on the use of POCUS in the neonatal and paediatric critical care (Continued)

\begin{tabular}{|c|c|c|c|}
\hline No. & Recommendation & $\begin{array}{l}\text { Level of } \\
\text { agreement }\end{array}$ & $\begin{array}{l}\text { Quality of } \\
\text { evidence }\end{array}$ \\
\hline 30. & POCUS should be used to detect germinal matrix and intraventricular haemorrhage (IVH) in neonates & $\begin{array}{l}\text { Strong } \\
\text { agreement }\end{array}$ & A \\
\hline 31. & $\begin{array}{l}\text { POCUS is helpful to detect cerebral blood flow patterns suggesting the presence of cerebral circulatory arrest in } \\
\text { children with fused skull bones }\end{array}$ & Agreement & C \\
\hline 32. & $\begin{array}{l}\text { POCUS is helpful to detect cerebral blood flow changes secondary to vasospasm in patients with traumatic brain } \\
\text { injury and non-traumatic intracranial bleeding. }\end{array}$ & Agreement & C \\
\hline 33. & $\begin{array}{l}\text { POCUS is helpful to detect changes in optic nerve sheath diameter (ONSD) indicative of raised ICP in children } \\
\text { with fused skull bones }\end{array}$ & Agreement & B \\
\hline 34. & POCUS is helpful to detect cerebral midline shift in neonates and children & Agreement & C \\
\hline 35. & POCUS is helpful for detection of free intra-abdominal fluid in neonates and children & $\begin{array}{l}\text { Strong } \\
\text { agreement }\end{array}$ & C \\
\hline 36. & $\begin{array}{l}\text { POCUS may detect parenchymal changes of abdominal organs in neonates and children [although for a definitive } \\
\text { diagnosis a detailed assessment should be performed by a paediatric radiologist] }\end{array}$ & Agreement & D \\
\hline 37. & $\begin{array}{l}\text { POCUS may detect obstructive uropathy in neonates and children [although for a definitive diagnosis a detailed } \\
\text { assessment should be performed by a paediatric radiologist] }\end{array}$ & Agreement & D \\
\hline 38. & POCUS may assess bowel peristalsis in neonates and children & Agreement & D \\
\hline 39. & $\begin{array}{l}\text { POCUS may recognise hypertrophic pyloric stenosis [although for a definitive diagnosis a detailed assessment } \\
\text { should be performed by a paediatric radiologist] }\end{array}$ & Disagreement & D \\
\hline 40. & POCUS my guide peritoneal drainage or aspiration of peritoneal fluid in neonates and children & $\begin{array}{l}\text { Strong } \\
\text { agreement }\end{array}$ & D \\
\hline 41. & $\begin{array}{l}\text { POCUS is helpful to detect signs of necrotising enterocolitis [although for a definitive diagnosis a detailed } \\
\text { assessment should be performed by a paediatric radiologist or a person with specific advanced ultrasound } \\
\text { training] }\end{array}$ & Agreement & C \\
\hline
\end{tabular}

of evidence $C$ ). POCUS can be used to assess cardiac function semi-quantitatively by assessing ejection fraction (EF) and fraction shortening (FS) $[14,15]$. In experienced hands, POCUS can be used for further assessment of left and right ventricular function as summarised in Table 2 [14, 15, 32-45]. However, a detailed assessment of cardiac function should be performed by a neonatologist/paediatric intensivist with advanced echocardiography training or a paediatric cardiologist.

6. POCUS is helpful for the assessment of pulmonary artery systolic pressure in pulmonary hypertension in neonates and children-strong agreement (quality of evidence B). In the presence of tricuspid regurgitation, pulmonary artery systolic pressure (PASP) can be reliably estimated using bedside POCUS. In the absence of right outflow tract obstruction, the regurgitation velocity represents the difference in pressure between the right atrium and the right ventricle. PASP is derived using a modified Bernoulli equation $[14,15,32]$.

7. POCUS is helpful for semi-quantitative assessment of pulmonary hypertension in neonates and children-strong agreement (quality of evidence $B$ ). In the absence of tricuspid regurgitation, POCUS can be used for semi-quantitative assessment of pulmonary hypertension by evaluating the interventricular septal position and movement at the end of systole and by assessing flow direction and velocities across a patent ductus arteriosus and/or foramen ovale [14, 15].

8. POCUS is helpful to diagnose pericardial effusion in neonates and children-strong agreement (quality of evidence B). Pericardial effusion can reliably be seen on POCUS by using multiple echocardiographic views $[15,46]$. Cardiac tamponade should be detected within the SAFE (Sonographic Assessment of liFe threatening Events) algorithm dedicated to recognise the main causes of life-threatening events in children [47].

9. POCUS is helpful to guide pericardiocentesis in neonates and children-strong agreement (quality of evidence B). Ultrasound-guided pericardiocentesis has lower complication rates compared to the traditional landmark technique [48-50].

10. POCUS should be used to assess the patency of ductus arteriosus-strong agreement (quality of evidence A). Cardiac POCUS can reliably be used to assess patency of ductus arteriosus in preterm infants [8-10]. In experienced hands, it may be used for hemodynamic evaluation of the ductus arteriosus [8, 10]. 
Table 2 Semi-quantitative systolic ventricular function measures that might be used by the clinician with more evolved training in cardiac POCUS. Normative values are taken from the available literature on the topic [32-45] and represent the best reference data available so far, although, in some cases, specific level for a different class of patients' age are lacking

\begin{tabular}{|c|c|c|c|}
\hline Parameter & View & Measurement & Reference values \\
\hline $\begin{array}{l}\text { LV fraction shortening } \\
\text { (FS\%) }\end{array}$ & $\begin{array}{l}\text { PSAX, PLAX, } \\
\text { ( } 2 \mathrm{D} \text { or } M \\
\text { mode) }\end{array}$ & LV intraluminal diameter change & $28-46 \%$ for all ages \\
\hline $\begin{array}{l}\text { LV ejection fraction } \\
\text { (Simpson's method) }\end{array}$ & $\mathrm{A} 4 \mathrm{C}, \mathrm{A} 2 \mathrm{C}$ & Percentage change of LV volume between end-diastole and end-systole & $55-80 \%$ for all ages \\
\hline $\begin{array}{l}\text { E-point septal } \\
\text { separation (EPSS) }\end{array}$ & $\begin{array}{l}\text { PLAX (2D or } \\
\text { M mode) }\end{array}$ & $\begin{array}{l}\text { Distance between anterior leaflet of the mitral valve and intraventricular } \\
\text { septum during the diastolic phase. This measurement is associated with } \\
\text { LV systolic volume. }\end{array}$ & $\begin{array}{l}>7 \mathrm{~mm} \text { in adults predictive of } \\
\text { severe LV dysfunction * }\end{array}$ \\
\hline $\begin{array}{l}\text { LV output (stroke } \\
\text { volume) }\end{array}$ & A5C, PLAX & $\begin{array}{l}\text { Product of VTI measured by pulse wave Doppler at LVOT in A5C and } \\
\text { LVOT cross-sectional area measured in PLAX }\end{array}$ & $\begin{array}{l}\text { Z-scores available for different } \\
\text { ages and should be used; } \\
\text { neonates: } 150-400 \mathrm{ml} / \mathrm{kg} / \mathrm{min}\end{array}$ \\
\hline $\begin{array}{l}\text { Mitral annular plane } \\
\text { systolic excursion } \\
\text { (MAPSE) }\end{array}$ & $\mathrm{A} 4 \mathrm{C}$ & $\begin{array}{l}\text { Systolic excursion of lateral (or medial) mitral annulus toward apex to } \\
\text { assess LV systolic function. }\end{array}$ & $\begin{array}{l}Z \text {-scores available for different } \\
\text { ages and should be used; } \\
\text { term neonates: > } 8 \mathrm{~mm}(8-11 \\
\mathrm{mm}) \\
\text { Adults 12-14 mm (<8 mm } \\
\text { predictive of severe LV } \\
\text { dysfunction) }\end{array}$ \\
\hline $\begin{array}{l}\text { RV output (stroke } \\
\text { volume) }\end{array}$ & $\begin{array}{l}\text { PSAX or } \\
\text { sweep PLAX }\end{array}$ & $\begin{array}{l}\text { Product of VTI measured by pulsed-wave Doppler at RVOT and RVOT } \\
\text { cross-sectional area }\end{array}$ & $\begin{array}{l}Z \text {-scores available for different } \\
\text { ages and should be used; } \\
\text { neonates: } 150-400 \mathrm{ml} / \mathrm{kg} / \mathrm{min}\end{array}$ \\
\hline $\begin{array}{l}\text { Tricuspid annular plane } \\
\text { systolic excursion } \\
\text { (TAPSE) }\end{array}$ & $\mathrm{A} 4 \mathrm{C}$ & $\begin{array}{l}\text { Systolic excursion of lateral (or medial) tricuspid annulus toward apex to } \\
\text { assess RV systolic function. }\end{array}$ & $\begin{array}{l}\text { Term neonates: > } 8 \text { mm (8-11 } \\
\text { mm) } \\
\text { Children-Z-score available; } \\
\text { generally > } 12 \text { mm (12-17 mm) } \\
\text { Adults or grown-up children > } \\
17 \mathrm{~mm}(17-25 \mathrm{~mm})\end{array}$ \\
\hline
\end{tabular}

A4C Apical 4 chamber view, A5C Apical 5 chamber view, A2C Apical 2 chamber view, PSAX parasternal short-axis view, PLAX parasternal long-axis view, M mode motion mode, $L V$ left ventricle, LVOT left ventricular outflow tract, VTI velocity time integral

*No data are available in neonates or children

11. POCUS may be used to detect vegetations to make a diagnosis of endocarditis [however, a definitive diagnosis requires a detailed assessment by a paediatric cardiologist or a person with advanced echocardiography training]-disagreement (quality of evidence D). There was no agreement on using POCUS for the diagnosis of endocarditis. Detecting vegetations to make a diagnosis of endocarditis should be done by more expert (paediatric cardiologist or by an intensivist with advanced POCUS skills, and not expected to rule out by neonatal and paediatric intensivists with competencies in basic POCUS). However, intracardiac masses may be detected on POCUS examination and should be referred to a paediatric cardiologist or a neonatologist/ paediatric intensivist with advanced echocardiography training $[51,52]$.

Semi-quantitative systolic ventricular function measures that may be used in POCUS have been summarised in Table 2 [32-45].
B. Recommendations for use of lung POCUS

1. POCUS is helpful to distinguish between respiratory distress syndrome (RDS) and transient tachypnoea of the neonate (TTN)-agreement (quality of evidence B). RDS is characterised by a poorly aerated lung with the absence of A-lines, presence of small "subpleural" consolidations and diffuse white lung (confluent B-lines). Conversely, in TTN, the interstitial pattern alternates with areas of nearnormal lung (with A-lines). Pleural line thickening might be seen in late preterm and term babies [53-61]. The double lung point has been proposed as a pathognomonic finding $[62,63]$ but it is debated, as it does not seem necessary for TTN diagnosis if normal lung areas are evident [64]. High inter-observer agreement between physicians with different lung ultrasound (LUS) expertise has been reported, which makes the differential diagnosis between RDS and TTN reliable, irrespective of the operator [65]. In preterm neonates with RDS, various studies showed that a semiquantitative ultrasound evaluation of 
lung aeration is very predictive of the need for surfactant $[66,67]$ and, therefore, this POCUS tool is helpful to decide about surfactant replacement and improve its timeliness [68].

2. POCUS is helpful to detect pneumonia in neonates and children-agreement (quality of evidence B). LUS signs of pneumonia are the presence of consolidations and dynamic air bronchograms, B-lines and pleural effusion. Abnormal pleural line and decreased lung sliding may be observed [58, 65]. LUS has been reported to have higher diagnostic accuracy compared with chest X-rays for the diagnosis of pneumonia [69]. However, there is no defined threshold for consolidation size or a consensual method of measurement.

3. POCUS is helpful to semi-quantitatively evaluate lung aeration and help the management of respiratory intervention in acute respiratory distress syndrome (ARDS) in neonates and children-agreement (quality of evidence B). LUS in neonatal and paediatric ARDS shows bilateral diffuse areas of reduced lung aeration with areas of the interstitial syndrome and consolidations, pleural line abnormalities and pleural effusion [70-73]. Although current diagnostic criteria for ARDS do not yet include LUS, it represents a useful tool for its detection [73, 74]. Several LUS aeration scores are used to semi-quantitatively measure the effect of fluid restriction, alveolar recruitment and surfactant administration [7579]. Scores based on the main lung ultrasound semiology (including A lines, alveolar-interstitial pattern and presence of consolidations) should be preferred over the simple B lines count, as they describe better the lung aeration and have been validated with various techniques [80].

4. POCUS is helpful to recognise meconium aspiration syndrome (MAS) - agreement (quality of evidence C). MAS is now recognised as a cause of neonatal ARDS [73] and shares the same LUS findings. However, this LUS pattern is dynamic and changes with the spread of meconium plugs during mechanical ventilation [81, 82].

5. POCUS is helpful for descriptive purposes in viral bronchiolitis but cannot provide a differential aetiological diagnosis-strong agreement (quality of evidence C). LUS signs in viral bronchiolitis consist of pleural line irregularities, "sub-pleural" consolidations and areas with interstitial pattern [83-85]. Good concordance between operators has been shown in wheezing infants [86]. LUS findings in viral bronchiolitis are similar to those seen during influenza outbreaks [87] but it is not currently possible to differentiate between different forms of viral respiratory infections.

6. POCUS is helpful to accurately detect pneumothorax in neonates and children-strong agreement (quality of evidence B). In adults, LUS has a high diagnostic accuracy for the diagnosis of pneumothorax $[88,89]$ and has been reported to be more sensitive than conventional radiology [90]. Neonatal data confirm this high diagnostic performance for tension pneumothorax [91].

7. POCUS is helpful to insert chest tube or perform needle aspiration in neonatal tension pneumothorax-strong agreement (quality of evidence B). LUS should not only be used to diagnose pneumothorax but also to provide static guidance for pleurocentesis [91]. Thus, POCUS should be used to identify lung margin, hemidiaphragm and sub-diaphragmatic organs throughout the respiratory cycle before needle or tube insertion to safely avoid them.

8. POCUS is helpful to detect pleural effusions in neonates and children-strong agreement (quality of evidence B). Policy statements in adults recommend the use of LUS for the detection of effusions and evaluation of pleural fluid volume to guide management [55, 92, 93]. In children, LUS shows high accuracy in the diagnosis of pneumonia-related pleural effusion [47].

9. POCUS is helpful to guide thoracentesis in neonates and children-strong agreement (quality of evidence B). Ultrasound-guided thoracentesis reduces the risk of complications and increases success rates $[55,92,93]$. It should be used to identify lung margin, hemidiaphragm and sub-diaphragmatic organs throughout the respiratory cycle before needle or tube insertion to safely avoid them.

10. POCUS is helpful to evaluate lung oedema in neonates and children-agreement (quality of evidence $C$ ). Although LUS is accurate in detecting extra-vascular lung fluid [94], it cannot distinguish between cardiogenic and noncardiogenic oedema [55, 94]. LUS has been used in children to evaluate cardiogenic lung oedema, by assessing extravascular lung fluid counting numbers of B-lines after cardiac surgery [79]. However, extravascular lung water may obviously be affected by the pressure delivered during mechanical ventilation. Thus, in these conditions, LUS globally evaluates the lung aeration rather than extravascular lung fluid. 
11. POCUS is helpful in detecting anaesthesiainduced atelectasis in neonates and children- $a$ greement (quality of evidence C). LUS may be used to monitor this complication during anaesthesia that may potentially lead to hypoxemia [95].

C. Recommendations for use of vascular POCUS in line placement

1. POCUS-guided technique should be used for internal jugular vein (IJV) line placement in neonates and children-strong agreement (quality of evidence A). Robust paediatric data favour ultrasound guidance for IJV cannulation compared to landmark technique [96-100]. Multiple studies have repeatedly shown decreased risk of cannulation failure and arterial puncture, higher success rates on first attempt and decreased incidence of complications [100104].

2. POCUS-guided technique is helpful for subclavian venous line placement in neonates and children-strong agreement (quality of evidence B). The subclavian and brachiocephalic veins have been cannulated in children and neonates (including preterm ones) with in-plane visualisation, and this seems the easiest approach [105-107]. However, there is no firm consensus about the best technique, i.e., supraclavicular vs infra-clavicular, or in-plane vs outof-plane [101, 108]. Multiple cases series of children and neonates reported higher success rates and decreased incidence of complications favouring ultrasound use compared to landmark technique. Therefore, ultrasound-guided subclavian cannulation in neonates and children is safe, doable and is advised over a blind cannulation technique [101, 107-112].

3. POCUS-guided technique is helpful for femoral line placement in neonates and children-strong agreement (quality of evidence B). Paediatric trials comparing US-guided femoral line placement with landmark technique showed higher overall success rate and on the first attempt as well as fewer needle passes [113-116].

4. POCUS-guided technique is helpful for arterial catheters placement in children-agreement (quality of evidence B): a few high-quality studies have found that US-guided arterial line placement is faster (shorter time to success and lower number of attempts) and has higher firstattempt cannulation rates regardless of the location $[117,118]$.

5. POCUS-guided technique is helpful for peripherally inserted central catheters (PICC) in children-agreement (quality of evidence B). A paediatric RCT comparing US-guided versus landmark PICC placement showed higher firstattempt cannulation rate, successful PICC positioning rate and shorter time to success when ultrasound was used [119]. Similar findings are supported by adult literature [120].

6. POCUS is helpful to locate catheter tip position in neonates and children-strong agreement (quality of evidence C). A trial and two observational studies in the paediatric and neonatal population have suggested that US may decrease radiation and number of line manipulations by confirming PICC tip position after placement [121-123] and could be considered a complement to conventional radiography [124].

D. Recommendations for use of cerebral POCUS

1. POCUS is helpful to detect cerebral blood flow changes in neonates and children-agreement (quality of evidence B). Children are especially amenable to cranial ultrasound since their skulls remain not yet ossified and their fontanelles open $[125,126]$. Alterations in cerebral blood flow allow inferences to be made regarding brain pathology and raised intracranial pressure (ICP) $[127,128]$. Estimation of flow velocities and calculation of pulsatility (PI) and resistance indexes (RI) are useful tools for non-invasive monitoring of ICP [129]. Age-dependent normal values of blood velocities in different vessels and indexes have been previously published [130]. Paediatric data are not yet sufficient to support its use and caution must be taken when interpreting results [131, 132].

2. POCUS should be used to detect germinal matrix and intraventricular haemorrhage (IVH) in neonates-strong agreement (quality of evidence $A$ ). Intraventricular haemorrhage and parenchymal bleeding remain a frequent and serious complication in extremely preterm infants. POCUS is a useful clinical tool to detect IVH and parenchymal changes [133], and assesses the severity according to Papile's classification [134, 135]. In environments where imaging resources are limited, brain POCUS should be used for the diagnosis of IVH which may aid in the redirection of care.

3. POCUS is helpful to detect cerebral blood flow patterns suggesting the presence of cerebral circulatory arrest in children with fused skull bones-agreement (quality of evidence C). Transcranial doppler has been used to establish the presence of cerebral circulatory arrest [135, 
136] by evaluation of the middle cerebral (MCA) and basilar artery. The following patterns are compatible with cerebral circulatory arrest $[126,136]$ : (a) oscillating waveform or sustained reversal of diastolic flow, (b) small systolic spikes and disappearance of all intra-cranial flow, (c) no flow in MCA, (d) reversal of diastolic flow in extracranial Internal Carotid Artery (ICA) and (e) mean velocity in MCA less than $10 \mathrm{~cm} / \mathrm{s}$ for more than $30 \mathrm{~min}$. However, interpretation of this assessment must be done with caution.

4. POCUS is helpful to detect cerebral blood flow changes secondary to vasospasm in patients with traumatic brain injury and non-traumatic intracranial bleeding-agreement (quality of evidence $C$ ). Vasospasm of cerebral arteries results in increased flow velocities. The Lindegaard ratio (LR) is calculated by dividing mean velocity in MCA by mean velocity in ipsilateral extracranial ICA. As hyperaemia may also increase mean velocities, LR is useful to distinguish between hyperaemia and vasospasm (3:6 ratio is considered a sign of mild vasospasm, and $>6$ a sign of severe vasospasm) [136].

5. POCUS is helpful to detect changes in optic nerve sheath diameter (ONSD) indicative of raised ICP in children with fused skull bones-agreement (quality of evidence B). Measurement of the ONSD is suggestive of papilledema and increased ICP [137, 138]; however, data conflict on threshold measurements [137-140] and papilledema may persist despite normalisation of intracranial pressure. Therefore, it must be reminded that this technique may have relevant measurement errors because of the narrow margins that distinguish pathological from normal.

6. POCUS is helpful to detect cerebral midline shift (MLS) in neonates and children-agreement (quality of evidence C). Measurement of the distance from both temporal bones to the centre of the third ventricle through the temporal acoustic window determines the presence of MLS [141, 142]. Minimal shifts (less than $5 \mathrm{~mm}$ ) in adults have proven to identify abnormal conditions [143]. Yet, normative values for MLS identification in children have not been reported, and this may reduce the helpfulness of this application.

E. Recommendations for abdominal POCUS

1. POCUS is helpful for the detection of free intraabdominal fluid in neonates and children-strong agreement (quality of evidence $C$ ).
Abdominal POCUS is widely used as a clinical tool for the management and diagnosis of patients with abdominal pathology [144-148]. Evaluation of free fluid is particularly useful when sudden clinical deterioration and hypotension occur and may provide insight into the ongoing pathophysiologic process [149, 150].

2. POCUS may detect parenchymal changes of abdominal organs in neonates and children [although for a definite diagnosis a detailed assessment should be performed by a paediatric radiologist] - agreement (quality of evidence D). Basic ultrasound knowledge of abdominal organ anatomy is essential during POCUS examination. Furthermore, a detailed assessment should be performed by a paediatric radiologist if abnormal abdominal organ structures are detected by POCUS $[151,152]$.

3. POCUS may detect obstructive uropathy in neonates and children [although for a definite diagnosis a detailed assessment should be performed by a paediatric radiologist]_agreement (quality of evidence D). A renal ultrasound is useful to easily detect the presence of hydronephrosis even by novices [152-154]. Urinary retention can be evaluated by POCUS assessing postvoid residual volumes. In the case of anuria, a simple obstruction requiring a urinary catheter placement can be ruled out.

4. POCUS may assess bowel peristalsis in neonates and children-agreement (quality of evidence D). Bowel POCUS may be used to assess peristalsis [155] but insufficient data yet exist correlating peristalsis with feeding tolerance. However, the presence of peristalsis has strong negative predictive value in adults for ileus and gut ischemia in adults [156].

5. POCUS may recognise hypertrophic pyloric stenosis [although for a definitive diagnosis a detailed assessment should be performed by a paediatric radiologist]_disagreement (quality of evidence D )[157]

6. POCUS may guide peritoneal drainage or aspiration of peritoneal fluid in neonates and children-strong agreement (quality of evidence $D$ ). A paracentesis may be required for either diagnostic or therapeutic purposes. POCUS should be used for pre-procedural planning, identification of epigastric vessels and real-time ultrasonographic guidance. In adult studies, the use of ultrasound has been shown to decrease both bleeding complications and the overall cost 
of care for patients undergoing in-hospital paracentesis [158].

7. POCUS is helpful to detect signs of necrotizing enterocolitis (NEC) [although for a definitive diagnosis a detailed assessment should be performed by a paediatric radiologist or a person with specific advanced ultrasound training]_agreement (quality of evidence $C$ ). Ultrasound may be a useful adjunct detecting changes consistent with NEC even when radiographs are inconclusive $[159,160]$. Furthermore, radiographs have poor sensitivity in the diagnosis of NEC $[161,162]$. POCUS can provide prognostic value identifying free fluid, bowel wall thickness, pneumatosis intestinalis, portal venous gas and vascular perfusion [159, 163-166]. The International Neonatal

Consortium's NEC subgroup recently revisited the necrotizing enterocolitis (NEC) pathogenesis and new diagnostic criteria were proposed [167]. These were based on the so-called 'two out of three' model which includes pneumatosis intestinalis or portal venous gas by abdominal X-rays and/or POCUS. POCUS was included since various studies demonstrated that it outperformed conventional radiology to this end [159].

\section{Discussion}

POCUS is increasingly being utilised in neonatal and paediatric critical care as a valuable adjunct to clinical examination. The use of POCUS by the clinician is different than a complete diagnostic study by the specialist and its role is dynamic - the same provider can perform and interpret the study, rapidly integrate this information within the current clinical setting, and then repeat the study to identify changes associated with the intervention. POCUS involves a focused assessment to answer a specific question, and it provides anatomical and/ or physiological information to be integrated with clinical and laboratory data and make timely and accurate decisions possible. The statements on which panellists disagreed concerned two particular indications (endocarditis and hypertrophic pyloric stenosis), whose diagnosis should be done by a detailed ultrasonography in the hands of an expert paediatric cardiologist or radiologist. The role of POCUS (i.e., point-of-care ultrasound performed directly by neonatal/paediatric intensivists at the bedside) for these indications is not clear, while the role of ultrasound, in general, is indeed important.

There remains a significant variation in clinical practice-in indications, training program and clinical governance. The application of POCUS in clinical practice is dependent on many factors including availability of ultrasound machines, providers, hospital setting, local patient population and specialty. Even within a unit, practice varies among clinicians and their expertise. We subdivided POCUS recommendations according to the estimated level of training required for their use (Fig. 2), and this may be helpful for their implementation.

Defining a scope of practice is fundamental for POCUS, and these ESPNIC guidelines have been developed for the targeted use of ultrasound in NICU and PICU by any neonatologist or paediatric intensivist. For most diagnostic (heart, lungs, brain and abdomen) and procedural (line placement and fluid drainage) POCUS applications, these guidelines can be used at all ages in children or neonates. However, while using cardiac POCUS in neonates, clinicians should be aware that undiagnosed critical congenital heart defects can present just during this period. They should acknowledge the limitations of skills, and it should not be used as a screening tool for diagnosing or excluding congenital heart defects. A patient with a suspected critical congenital heart defect should be quickly referred to a paediatric cardiologist, even if this implies out-ofhospital patient's transportation. However, in cases of suspicion of a non-critical defect or for patients with low pre-test probability a more expectative management can be provided. Moreover, the use of pulse-oximetry screening for congenital heart defects is useful and should be integrated into the clinical decision-making process, as internationally recommended $[168,169]$.

These guidelines may help in standardising clinical practice across acute care settings and physicians. It is not meant to be prescriptive, but rather to outline the

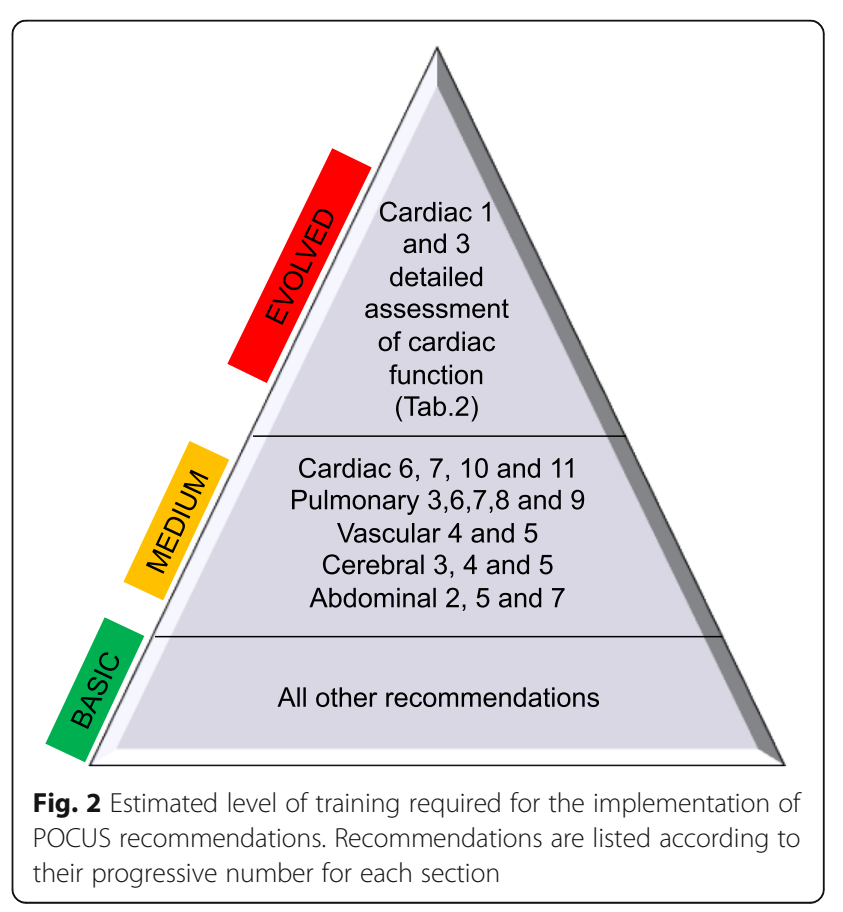


important features of structured POCUS applications in clinical practice. The use of these guidelines often will not have any cost implication for the equipment, as ultrasound machine is almost always available in most neonatal and paediatric intensive care units. ESPNIC will promote the diffusion of these guidelines by appropriate advertisement, links and presentation in the society congresses and training events.

These guidelines have strengths and limitations as any other. Strengths are represented by (1) the fairly subdivided multidisciplinary panellists' group (including both neonatologists and paediatric intensivists, expert in different POCUS areas and coming from different geographical regions), and (2) the use of a standardised methodology. In several fields, these recommendations are based upon a few studies with moderate/low evidence or based upon experts' opinions and this is a striking difference compared to similar guidelines in adult critical care. In fact, authors answered to following PICO questions: "Does point-of-care ultrasound for heart/lung/line placement/abdomen/brain provide any clinical advantage in neonatal or paediatric intensive care practice?" (supplementary methods). These questions were purposely quite general, as POCUS is not a therapeutic intervention, but rather a diagnostic and monitoring technique and we expected few randomised controlled trials or high-quality diagnostic accuracy studies about POCUS specifically aiming to improve any particular paediatric/neonatal outcome. Moreover, some of the POCUS applications may not be immediately used in all intensive care units as in ours, because of the specific expertise required in some particular contexts (such as the extremely preterm neonates or non-sedated and non-collaborative patients). However, the existence of formal guidelines may help to improve the local expertise and foster new studies to expand knowledge in this field and refine future recommendations. This is extremely important as further studies are warranted to demonstrate that POCUS actually improves patients' management and outcome, similar to what has been demonstrated in adult critical care $[1-7,55]$. Another concern is that the clinicians involved are all enthusiastic users of POCUS and this may have theoretically contributed to have 'too positive' recommendations. The ESPNIC POCUS Working Group recognises that there are emerging indications for POCUS outside of those listed here and needs for future research steps. Publication of new literature may require future revision and ESPNIC POCUS Working Group is willing to update guidelines accordingly every 3 years.

These guidelines may provide a substrate to develop a POCUS curriculum and structured training programs, which are urgently needed for quality assurance. This guideline paper is not a training statement: requirements and methods of POCUS training should be a sensible follow-up article to this one.

\section{Conclusions}

Despite the lack of published evidence-based guidelines specifically for its use in the neonatal and paediatric intensive care units, POCUS is increasingly being used. ESPNIC POCUS guidelines provide the substrate to optimise POCUS use in neonatal and paediatric critical care and guide future research steps according to currently unmet needs. Guidelines may help in making the clinical practice standardised and clinical governance robust.

\section{Supplementary information}

Supplementary information accompanies this paper at https://doi.org/10. 1186/s13054-020-2787-9.

Additional file 1. Online supplementary material.

\section{Abbeviations}

A4C: Apical 4-chamber; ARDS: Acute respiratory distress syndrome; CPU: Clinician performed ultrasound; EF: Ejection fraction; ESPNIC: European Society of Paediatric and Neonatal Intensive Care; FS: Fraction shortening; ICP: Intracranial pressure; IJV: Internal jugular vein; IVC: Inferior vena-cava; IVH: Intraventricular haemorrhage; LR: Lindegaard ratio; LUS: Lung ultrasound; LVOT: Left ventricular outflow tract; MAS: Meconium aspiration syndrome; MCA: Middle cerebral artery; MLS: Cerebral midline shift; NEC: Necrotizing enterocolitis; NICU: Neonatal intensive care unit; NPE: Neonatologist performed echocardiography; ONSD: Optic nerve sheath diameter; PASP: Pulmonary artery systolic pressure; PI: Pulsatility index; PICC: Peripherally inserted central catheters; PICU: Pediatric intensive care unit; PLAX: Parasternal long; POCUS: Point of care ultrasound; PSAX: Short axis; RDS: Respiratory distress syndrome; RI: Resistance index; TTN: Transient tachypnoea of the neonate; VTIs: Variation of velocity-time integrals

\section{Acknowledgements}

Not applicable

\section{Authors' contributions}

YS, CT and DDL conceptualised and designed the development of the whole project. YS and CT wrote the first manuscript draft. DDL took care of the whole methodology and supervised the whole project. All authors performed literature search and analysis, interpreted the literature data with their specific expertise, participate in meetings discussions and voted on recommendations and manuscript preparation. Moreover, all authors critically reviewed the manuscript for important intellectual content, approved it in its final version and agreed to be accountable for all aspects of the work. The participation to the project did not entail any honorarium. All authors read and approved the final manuscript.

\section{Funding}

This project has no funding. ESPNIC provided technical and secretarial assistance for free.

\section{Availability of data and materials}

Data sharing is not applicable to this article as no datasets were generated or analysed during the current study.

Ethics approval and consent to participate

Not applicable.

Consent for publication

Not applicable.

Competing interests

The authors declare that they have no competing interests. 


\section{Author details}

${ }^{1}$ Department of Paediatrics - Neonatology and Paediatric Cardiology, Cambridge University Hospitals and University of Cambridge School of Clinical Medicine, Biomedical Campus, Hills Road, Cambridge CB2 0QQ, UK. ${ }^{2}$ Addenbrooke's Hospital, Box 402, Cambridge, UK. ${ }^{3}$ Paediatric Cardiology, Centre de Pédiatrie, Clinique des Grangettes, Geneva, Switzerland. ${ }^{4}$ Department of Paediatrics, Children's Hospital of Philadelphia and Perelman School of Medicine, Philadelphia, USA. ${ }^{5}$ Division of Paediatrics and Neonatal Critical Care, APHP - Paris Saclay University Hospitals, "A. Béclère" Medical centre, Paris, France. ${ }^{6}$ Department of Paediatric Intensive Care, Gregorio Marañón General University Hospital, Madrid, Spain. ${ }^{7}$ Department of Paediatric Cardiology, Sant Joan de Déu Hospital, Barcelona, Spain. ${ }^{8}$ Department of Paediatric Intensive Care, Great Ormond Street Hospital, London, UK. ${ }^{9}$ Department of Paediatric Intensive Care, Hospital Universitario Central de Asturias, Oviedo. CIBER-Enfermedades Respiratorias. Instituto de Salud Carlos III, Madrid. Instituto de Investigación Sanitaria del Principado de Asturias, Oviedo, Spain. ${ }^{10}$ Department of Paediatric Intensive Care, Nottingham University Hospitals, Nottingham, UK. " Department of Paediatric and Cardiac Intensive Care, Children's Hospital Colorado, Aurora, USA. ${ }^{12}$ Division of Paediatric Critical Care, APHP - Paris Saclay University Hospitals, "Kremlin Bicetre" Medical Centre, Paris, France. ${ }^{13}$ Department of Paediatric Anaesthesia and Intensive Care, Children's Hospital Banska Bystrica, Banska Bystrica, Slovakia. ${ }^{14}$ Department of Paediatrics, Medicins Sans Frontieres (Suisse), Geneva, Switzerland. ${ }^{15}$ Department of Anaesthesiology and Critical Care Medicine, Children's Hospital of Philadelphia and Perelman School of Medicine, Philadelphia, USA. ${ }^{16}$ Department of Paediatrics, Division of Paediatric Critical Care Medicine, Beatrix Children's Hospital Groningen, University Medical Center Groningen, Groningen, The Netherlands.

${ }^{17}$ Physiopathology and Therapeutic Innovation Unit-INSERM Unit U999, South Paris Medical School, Paris Saclay University, Paris, France.

\section{Received: 9 December 2019 Accepted: 14 February 2020} Published online: 24 February 2020

\section{References}

1. On behalf of The Canadian Internal Medicine Ultrasound (CIMUS) Group*, Ma IWY, Arishenkoff S, Wiseman J, Desy J, Ailon J, et al. Internal Medicine Point-of-Care Ultrasound Curriculum: Consensus Recommendations from the Canadian Internal Medicine Ultrasound (CIMUS) Group. J Gen Intern Med. 2017;32:1052-7.

2. Expert Round Table on Ultrasound in ICU. International expert statement on training standards for critical care ultrasonography. Intensive Care Med. 2011;37:1077-83.

3. Frankel HL, Kirkpatrick AW, Elbarbary M, Blaivas M, Desai H, Evans D, et al. Guidelines for the appropriate use of bedside general and cardiac ultrasonography in the evaluation of critically ill patients—-part I: general ultrasonography. Crit Care Med. 2015;43:2479-502.

4. Moore CL, Copel JA. Point-of-care ultrasonography. N Engl J Med. 2011;364: 749-57.

5. Evans N, Gournay V, Cabanas F, Kluckow M, Leone T, Groves A, et al. Pointof-care ultrasound in the neonatal intensive care unit: international perspectives. Semin Fetal Neonatal Med. 2011;16:61-8.

6. Longjohn M, Wan J, Joshi V, Pershad J. Point-of-care echocardiography by pediatric emergency physicians. Pediatr Emerg Care. 2011;27:693-6.

7. Vignon P, Dugard A, Abraham J, Belcour D, Gondran G, Pepino F, et al. Focused training for goal-oriented hand-held echocardiography performed by noncardiologist residents in the intensive care unit. Intensive Care Med. 2007;33:1795-9.

8. Mertens L, Seri I, Marek J, Arlettaz R, Barker P, McNamara P, et al. Targeted neonatal echocardiography in the neonatal intensive care unit: practice guidelines and recommendations for training. J Am Soc Echocardiogr. 2011; 24:1057-78.

9. Singh Y, Gupta S, Groves AM, Gandhi A, Thomson J, Qureshi S, et al. Expert consensus statement 'neonatologist-performed echocardiography (NoPE)'-training and accreditation in UK. Eur J Pediatr. 2016;175:281-7.

10. de Boode WP, Singh Y, Gupta S, Austin T, Bohlin K, Dempsey E, et al. Recommendations for neonatologist performed echocardiography in Europe: consensus statement endorsed by European Society for Paediatric Research (ESPR) and European Society for Neonatology (ESN). Pediatr Res. 2016:80:465-71.
11. Australasian Society for Ultrasound Medicine. Proficiency \& Appropriate Use Statement [Internet]. Available from: https://www.asum.com.au/files/public/ SoP/Current/Paediatrics_and_Neo-Natal/Proficiency-and-Appropriate-UseStatement-for-Neonatal-Ultrasound-G1.pdf.

12. Kneyber MCJ, de Luca D, Calderini E, Jarreau P-H, Javouhey E, Lopez-Herce $J$, et al. Recommendations for mechanical ventilation of critically ill children from the Paediatric Mechanical Ventilation Consensus Conference (PEMVECC). Intensive Care Med. 2017:43:1764-80.

13. Brouwers MC, Kerkvliet K, Spithoff K, AGREE Next Steps Consortium. The AGREE Reporting Checklist: a tool to improve reporting of clinical practice guidelines. BMJ. 2016;352:11152

14. Singh Y. Echocardiographic evaluation of hemodynamics in neonates and children. Front Pediatr. 2017;5:201.

15. Lang RM, Bierig M, Devereux RB, Flachskampf FA, Foster E, Pellikka PA, et al. Recommendations for chamber quantification: a report from the American Society of Echocardiography's guidelines and standards committee and the chamber quantification writing group, developed in conjunction with the European Association of Echocardiography, a branch of the European Society of Cardiology. J Am Soc Echocardiogr. 2005;18:1440-63.

16. Feissel M, Michard F, Faller J-P, Teboul J-L. The respiratory variation in inferior vena cava diameter as a guide to fluid therapy. Intensive Care Med. 2004;30:1834-7.

17. Barbier C, Loubières $Y$, Schmit C, Hayon J, Ricôme J-L, Jardin F, et al. Respiratory changes in inferior vena cava diameter are helpful in predicting fluid responsiveness in ventilated septic patients. Intensive Care Med. 2004; 30:1740-6.

18. Levitov A, Marik PE. Echocardiographic assessment of preload responsiveness in critically ill patients. Cardiol Res Pract. 2012;2012:819696.

19. Lin EE, Chen AE, Panebianco N, Conlon T, Ju NR, Carlson D, et al. Effect of inhalational anesthetics and positive-pressure ventilation on ultrasound assessment of the great vessels: a prospective study at a children's hospital. Anesthesiology. 2016;124:870-7.

20. Via G, Tavazzi G, Price S. Ten situations where inferior vena cava ultrasound may fail to accurately predict fluid responsiveness: a physiologically based point of view. Intensive Care Med. 2016;42:1164-7.

21. Slama M, Masson H, Teboul J-L, Arnout M-L, Susic D, Frohlich E, et al. Respiratory variations of aortic VTI: a new index of hypovolemia and fluid responsiveness. Am J Physiol Heart Circ Physiol. 2002;283:H1729-33.

22. Feissel M, Michard F, Mangin I, Ruyer O, Faller JP, Teboul JL. Respiratory changes in aortic blood velocity as an indicator of fluid responsiveness in ventilated patients with septic shock. Chest. 2001;119:867-73.

23. Bates S, Odd D, Luyt K, Mannix P, Wach R, Evans D, et al. Superior vena cava flow and intraventricular haemorrhage in extremely preterm infants. J Matern Fetal Neonatal Med. 2016;29:1581-7.

24. Kluckow M, Evans N. Superior vena cava flow in newborn infants: a novel marker of systemic blood flow. Arch Dis Child Fetal Neonatal Ed. 2000;82: F182-7.

25. Lee A, Liestøl K, Nestaas E, Brunvand L, Lindemann R, Fugelseth D. Superior vena cava flow: feasibility and reliability of the off-line analyses. Arch Dis Child Fetal Neonatal Ed. 2010;95:F121-5.

26. Groves AM, Kuschel CA, Knight DB, Skinner JR. Echocardiographic assessment of blood flow volume in the superior vena cava and descending aorta in the newborn infant. Arch Dis Child Fetal Neonatal Ed. 2008;93:F24-8.

27. Ficial B, Bonafiglia E, Padovani EM, Prioli MA, Finnemore AE, Cox DJ, et al. A modified echocardiographic approach improves reliability of superior vena caval flow quantification. Arch Dis Child Fetal Neonatal Ed. 2017;102:F7-11.

28. Pereira de Souza Neto E, Grousson S, Duflo F, Ducreux C, Joly H, Convert J, et al. Predicting fluid responsiveness in mechanically ventilated children under general anaesthesia using dynamic parameters and transthoracic echocardiography. Br J Anaesth. 2011;106:856-64.

29. Renner J, Broch O, Duetschke P, Scheewe J, Höcker J, Moseby M, et al. Prediction of fluid responsiveness in infants and neonates undergoing congenital heart surgery. Br J Anaesth. 2012;108:108-15.

30. Choi DY, Kwak HJ, Park HY, Kim YB, Choi CH, Lee JY. Respiratory variation in aortic blood flow velocity as a predictor of fluid responsiveness in children after repair of ventricular septal defect. Pediatr Cardiol. 2010;31:1166-70.

31. Ficial B, Finnemore AE, Cox DJ, Broadhouse KM, Price AN, Durighel G, et al. Validation study of the accuracy of echocardiographic measurements of systemic blood flow volume in newborn infants. J Am Soc Echocardiogr. 2013;26:1365-71. 
32. Jain A, Mohamed A, El-Khuffash A, Connelly KA, Dallaire F, Jankov RP, et al. A comprehensive echocardiographic protocol for assessing neonatal right ventricular dimensions and function in the transitional period: normative data and z scores. J Am Soc Echocardiogr. 2014;27:1293-304.

33. McKaigney CJ, Krantz MJ, La Rocque CL, Hurst ND, Buchanan MS, Kendall JL. E-point septal separation: a bedside tool for emergency physician assessment of left ventricular ejection fraction. Am J Emerg Med. 2014;32: 493-7.

34. Matzer L, Cortada X, Ferrer P, De Armendi F, Kinney EL. Widened E point septal separation in a normal pediatric population. Chest. 1985;87:73-5.

35. Engle SJ, DiSessa TG, Perloff JK, Isabel-Jones J, Leighton J, Gross K, et al. Mitral valve $E$ point to ventricular septal separation in infants and children. Am J Cardiol. 1983:52:1084-7.

36. D'Cruz IA, Lalmalani GG, Sambasivan V, Cohen HC, Glick G. The superiority of mitral E point-ventricular septum separation to other echocardiographic indicators of left ventricular performance. Clin Cardiol. 1979;2:140-5.

37. Lew W, Henning H, Schelbert H, Karliner JS. Assessment of mitral valve $E$ point-septal separation as an index of left ventricular performance in patients with acute and previous myocardial infarction. Am J Cardiol. 1978; 41:836-45.

38. Favia I, Romagnoli S, Di Chiara L, Ricci Z. Predicting fluid responsiveness in children undergoing cardiac surgery after cardiopulmonary bypass. Pediatr Cardiol. 2017:38:787-93.

39. Pees C, Glagau E, Hauser J, Michel-Behnke I. Reference values of aortic flow velocity integral in 1193 healthy infants, children, and adolescents to quickly estimate cardiac stroke volume. Pediatr Cardiol. 2013;34:1194-200.

40. Hashimoto I, Watanabe K. Z-score of mitral annular plane systolic excursion is a useful Indicator of evaluation of left ventricular function in patients with acute-phase Kawasaki disease. Pediatr Cardiol. 2017;38:1057-64.

41. Terada T, Mori K, Inoue M, Yasunobu H. Mitral annular plane systolic excursion/left ventricular length (MAPSE/L) as a simple index for assessing left ventricular longitudinal function in children. Echocardiography. 2016;33: 1703-9.

42. Koestenberger M, Ravekes W, Avian A, Grangl G, Burmas A, Raith W, et al. Right ventricular outflow tract (RVOT) changes in children with an atrial septal defect: focus on RVOT velocity time integral, RVOT diameter, and RVOT systolic excursion. Echocardiography. 2016;33:1389-96.

43. McLaughlin ES, Travers C, Border WL, Deshpande S, Sachdeva R. Tricuspid annular plane systolic excursion as a marker of right ventricular dysfunction in pediatric patients with dilated cardiomyopathy. Echocardiography. 2017; 34:102-7.

44. Goldberg DJ, French B, Szwast AL, McBride MG, Paridon SM, Rychik J, et al. Tricuspid annular plane systolic excursion correlates with exercise capacity in a cohort of patients with hypoplastic left heart syndrome after Fontan operation. Echocardiography. 2016:33:1897-902.

45. Koestenberger M, Nagel B, Ravekes W, Avian A, Heinzl B, Cvirn G, et al. Reference values of tricuspid annular peak systolic velocity in healthy pediatric patients, calculation of z score, and comparison to tricuspid annular plane systolic excursion. Am J Cardiol. 2012;109:116-21.

46. Nagdev A, Stone MB. Point-of-care ultrasound evaluation of pericardial effusions: does this patient have cardiac tamponade? Resuscitation. 2011;82: 671-3.

47. Raimondi F, Yousef N, Migliaro F, Capasso L, De Luca D. Point-of-care lung ultrasound in neonatology: classification into descriptive and functional applications. Pediatr Res. 2018; [cited 2019 Jan 14]; Available from: http:// www.nature.com/articles/s41390-018-0114-9.

48. Tsang TS, Freeman WK, Sinak LJ, Seward JB. Echocardiographically guided pericardiocentesis: evolution and state-of-the-art technique. Mayo Clin Proc. 1998;73:647-52

49. Nagdev A, Mantuani D. A novel in-plane technique for ultrasound-guided pericardiocentesis. Am J Emerg Med. 2013;31:1424 e5-9.

50. Spurney CF, Sable CA, Berger JT, Martin GR. Use of a hand-carried ultrasound device by critical care physicians for the diagnosis of pericardial effusions, decreased cardiac function, and left ventricular enlargement in pediatric patients. J Am Soc Echocardiogr. 2005;18:313-9.

51. Gaspar HA, Morhy SS, Lianza AC, de Carvalho WB, Andrade JL, do Prado RR, et al. Focused cardiac ultrasound: a training course for pediatric intensivists and emergency physicians. BMC Med Educ. 2014;14:25.

52. Pershad J, Myers S, Plouman C, Rosson C, Elam K, Wan J, et al. Bedside limited echocardiography by the emergency physician is accurate during evaluation of the critically ill patient. Pediatrics. 2004;114:e667-71.
53. Escourrou G, De Luca D. Lung ultrasound decreased radiation exposure in preterm infants in a neonatal intensive care unit. Acta Paediatr. 2016;105: e237-9.

54. Cattarossi L, Copetti R, Poskurica B. Radiation exposure early in life can be reduced by lung ultrasound. Chest. 2011;139:730-1.

55. International Liaison Committee on Lung Ultrasound (ILC-LUS) for the International Consensus Conference on Lung Ultrasound (ICC-LUS), Volpicelli G, Elbarbary M, Blaivas M, Lichtenstein DA, Mathis G, et al. International evidence-based recommendations for point-of-care lung ultrasound. Intensive Care Med. 2012;38:577-91.

56. Liu J, Wang Y, Fu W, Yang C-S, Huang J-J. Diagnosis of Neonatal Transient Tachypnea and Its Differentiation From Respiratory Distress Syndrome Using Lung Ultrasound. Medicine. 2014;93:e197.

57. Liu J, Chen X-X, Li X-W, Chen S-W, Wang Y, Fu W. Lung ultrasonography to diagnose transient tachypnea of the newborn. Chest. 2016;149:1269-75.

58. Chen S-W, Fu W, Liu J, Wang Y. Routine application of lung ultrasonography in the neonatal intensive care unit. Medicine. 2017;96:e5826.

59. Sawires HK, Abdel Ghany EA, Hussein NF, Seif HM. Use of lung ultrasound in detection of complications of respiratory distress syndrome. Ultrasound Med Biol. 2015;41:2319-25.

60. Copetti R, Cattarossi L, Macagno F, Violino M, Furlan R. Lung ultrasound in respiratory distress syndrome: a useful tool for early diagnosis. Neonatology. 2008;94:52-9.

61. Vergine M, Copetti R, Brusa G, Cattarossi L. Lung ultrasound accuracy in respiratory distress syndrome and transient tachypnea of the newborn. Neonatology. 2014;106:87-93.

62. Copetti R, Cattarossi L. The 'double lung point': an ultrasound sign diagnostic of transient tachypnea of the newborn. Neonatology. 2007;91: 203-9.

63. Raimondi F, Migliaro F, De Luca D, Yousef N, Rodriguez FJ. Clinical Data Are Essential to Validate Lung Ultrasound. Chest. 2016;149:1575.

64. Raimondi F, Yousef N, Rodriguez Fanjul J, De Luca D, Corsini I, ShankarAguilera $\mathrm{S}$, et al. A multicenter lung ultrasound study on transient tachypnea of the neonate. Neonatology. 2019;115:263-8.

65. Brusa G, Savoia M, Vergine M, Bon A, Copetti R, Cattarossi L. Neonatal lung sonography: interobserver agreement between physician interpreters with varying levels of experience. J Ultrasound Med. 2015; 34:1549-54.

66. Razak A, Faden M. Neonatal lung ultrasonography to evaluate need for surfactant or mechanical ventilation: a systematic review and meta-analysis. Arch Dis Child Fetal Neonatal Ed. 2019. https://doi.org/10.1136/archdischild2019-316832. [Epub ahead of print]

67. De Martino L, Yousef N, Ben-Ammar R, Raimondi F, Shankar-Aguilera S, De Luca D. Lung ultrasound score predicts surfactant need in extremely preterm neonates. Pediatrics. 2018;142(3). https://doi.org/10.1542/peds.20180463. Epub 2018 Aug 14.

68. Raschetti R, Yousef N, Vigo G, Marseglia G, Centorrino R, Ben-Ammar R, et al. Echography-guided surfactant therapy to improve timeliness of surfactant replacement: a quality improvement project. J Pediatr. 2019; 212:137-43 e1.

69. Pereda MA, Chavez MA, Hooper-Miele CC, Gilman RH, Steinhoff MC, Ellington LE, et al. Lung ultrasound for the diagnosis of pneumonia in children: a meta-analysis. Pediatrics. 2015;135:714-22.

70. Acute Respiratory Distress Syndrome. The Berlin Definition. JAMA. 2012;307 [cited 2019 Jan 15]. Available from: http://jama.jamanetwork.com/article. aspx?doi=10.1001/jama.2012.5669.

71. On behalf of Respiratory Section of the European Society for Pediatric Neonatal Intensive Care (ESPNIC), De Luca D, Piastra M, Chidini G, Tissieres $P$, Calderini $E$, et al. The use of the Berlin definition for acute respiratory distress syndrome during infancy and early childhood: multicenter evaluation and expert consensus. Intensive Care Med. 2013;39:2083-91.

72. Khemani RG, Smith LS, Zimmerman JJ, Erickson S. Pediatric acute respiratory distress syndrome: definition, incidence, and epidemiology. Pediatr Crit Care Med. 2015;16:S23-40.

73. De Luca D, van Kaam AH, Tingay DG, Courtney SE, Danhaive O, Carnielli VP, et al. The Montreux definition of neonatal ARDS: biological and clinical background behind the description of a new entity. Lancet Respir Med. 2017:5:657-66.

74. De Luca D, van Kaam AH, Tingay DG, Courtney SE, Danhaive O, Carnielli VP, et al. Lung ultrasound and neonatal ARDS: is Montreux closer to Berlin than to Kigali? - authors' reply. Lancet Respir Med. 2017;5:e32. 
75. Brat R, Yousef N, Klifa R, Reynaud S, Shankar Aguilera S, De Luca D. Lung ultrasonography score to evaluate oxygenation and surfactant need in neonates treated with continuous positive airway pressure. JAMA Pediatr. 2015;169:e151797.

76. Bouhemad B, Brisson H, Le-Guen M, Arbelot C, Lu Q, Rouby J-J. Bedside ultrasound assessment of positive end-expiratory pressure-induced lung recruitment. Am J Respir Crit Care Med. 2011;183:341-7.

77. CAR'Echo Collaborative Network, AzuRea Collaborative Network, Haddam M, Zieleskiewicz L, Perbet S, Baldovini A, et al. Lung ultrasonography for assessment of oxygenation response to prone position ventilation in ARDS. Intensive Care Med. 2016;42:1546-56.

78. Mongodi S, Bouhemad B, Orlando A, Stella A, Tavazzi G, Via G, et al. Modified lung ultrasound score for assessing and monitoring pulmonary aeration. Ultraschall Med. 2017;38:530-7.

79. Kaskinen AK, Martelius L, Kirjavainen T, Rautiainen P, Andersson S, Pitkänen OM. Assessment of extravascular lung water by ultrasound after congenital cardiac surgery: lung ultrasound after congenital cardiac surgery. Pediatr Pulmonol. 2017:52:345-52.

80. De Luca D. Semi-quantititative lung ultrasound scores are accurate and useful and in critical care, irrespective of patients' age: the power of data over opinions. J Ultrasound Med. 2020.

81. Liu J, Cao H-Y, Fu W. Lung ultrasonography to diagnose meconium aspiration syndrome of the newborn. J Int Med Res. 2016;44:1534-42.

82. Piastra M, Yousef $N$, Brat R, Manzoni P, Mokhtari M, De Luca D. Lung ultrasound findings in meconium aspiration syndrome. Early Hum Dev. 2014;90:S41-3.

83. Caiulo VA, Gargani L, Caiulo S, Fisicaro A, Moramarco F, Latini G, et al. Lung ultrasound in bronchiolitis: comparison with chest X-ray. Eur J Pediatr. 2011; 170:1427-33.

84. Basile V, Di Mauro A, Scalini E, Comes P, Lofù I, Mostert M, et al. Lung ultrasound: a useful tool in diagnosis and management of bronchiolitis. BMC Pediatrics. 2015; [cited 2019 Jan 15];15. Available from: http:// bmcpediatr.biomedcentral.com/articles/10.1186/s12887-015-0380-1.

85. Taveira M, Yousef N, Miatello J, Roy C, Claude C, Boutillier B, et al. Un score échographique pulmonaire simple peut-il prédire la durée de ventilation des nourrissons atteints de bronchiolite aiguë sévère ? Arch Pediatr. 2018; 25:112-7.

86. Varshney T, Mok E, Shapiro AJ, Li P, Dubrovsky AS. Point-of-care lung ultrasound in young children with respiratory tract infections and wheeze. Emerg Med J. 2016:33:603-10.

87. Tsung JW, Kessler DO, Shah VP. Prospective application of clinicianperformed lung ultrasonography during the $2009 \mathrm{H} 1 \mathrm{~N} 1$ influenza a pandemic: distinguishing viral from bacterial pneumonia. Crit Ultrasound J. 2012;4:16

88. Cattarossi L, Copetti R, Brusa G, Pintaldi S. Lung ultrasound diagnostic accuracy in neonatal pneumothorax. Can Respir J. 2016;2016:1-5.

89. Liu J, Chi J-H, Ren X-L, Li J, Chen Y-J, Lu Z-L, et al. Lung ultrasonography to diagnose pneumothorax of the newborn. Am J Emerg Med. 2017;35:1298302.

90. Alrajab S, Youssef AM, Akkus NI, Caldito G. Pleural ultrasonography versus chest radiography for the diagnosis of pneumothorax: review of the literature and meta-analysis. Crit Care. 2013;17:R208.

91. Raimondi F, Rodriguez Fanjul J, Aversa S, Chirico G, Yousef N, De Luca D, et al. Lung Ultrasound for Diagnosing Pneumothorax in the Critically III Neonate. J Pediatr. 2016:175:74-8 e1.

92. Dancel R, Schnobrich D, Puri N, Franco-Sadud R, Cho J, Grikis L, et al. Recommendations on the use of ultrasound guidance for adult thoracentesis: a position statement of the Society of Hospital Medicine. J Hosp Med. 2018;13:126-35.

93. Havelock T, Teoh R, Laws D, Gleeson F, BTS Pleural Disease Guideline Group. Pleural procedures and thoracic ultrasound: British Thoracic Society Pleural Disease Guideline 2010. Thorax. 2010;65(Suppl 2):ii6176.

94. Volpicelli G, Skurzak S, Boero E, Carpinteri G, Tengattini M, Stefanone V, et al. Lung ultrasound predicts well extravascular lung water but is of limited usefulness in the prediction of wedge pressure. Anesthesiology. 2014;121: 320-7.

95. Acosta CM, Maidana GA, Jacovitti D, Belaunzarán A, Cereceda S, Rae E, et al. Accuracy of Transthoracic Lung Ultrasound for Diagnosing Anesthesiainduced Atelectasis in Children. Anesthesiology. 2014;120:1370-9.
96. de Souza TH, Brandão MB, Santos TM, Pereira RM, Nogueira RJN. Ultrasound guidance for internal jugular vein cannulation in PICU: a randomised controlled trial. Arch Dis Child. 2018;103:952-6.

97. Zanolla GR, Baldisserotto M, Piva J. How useful is ultrasound guidance for internal jugular venous access in children? J Pediatr Surg. 2018;53:789-93.

98. Verghese ST, McGill WA, Patel RI, Sell JE, Midgley FM, Ruttimann UE. Comparison of three techniques for internal jugular vein cannulation in infants. Paediatr Anaesth. 2000;10:505-11.

99. Verghese ST, McGill WA, Patel RI, Sell JE, Midgley FM, Ruttimann UE. Ultrasound-guided internal jugular venous cannulation in infants: a prospective comparison with the traditional palpation method. Anesthesiology. 1999;91:71-7.

100. de Souza TH, Brandão MB, Nadal JAH, Nogueira RJN. Ultrasound guidance for pediatric central venous catheterization: a meta-analysis. Pediatrics. 2018; 142.

101. Brass P, Hellmich M, Kolodziej L, Schick G, Smith AF. Ultrasound guidance versus anatomical landmarks for subclavian or femoral vein catheterization. Cochrane Database Syst Rev. 2015;1:CD011447.

102. Oulego-Erroz I, González-Cortes R, García-Soler P, Balaguer-Gargallo M, FríasPérez M, Mayordomo-Colunga J, et al. Ultrasound-guided or landmark techniques for central venous catheter placement in critically ill children. Intensive Care Med. 2018;44:61-72.

103. Hosokawa K, Shime N, Oulego-Erroz I, González-Cortes R, Rodríguez-Núñez A. Ultrasound-guided central venous catheter placement in children: what is a really good practice? Intensive Care Med. 2018;44:546-7.

104. Montes-Tapia F, Rodríguez-Taméz A, Cura-Esquivel I, Barreto-Arroyo I, Hernández-Garduño A, Rodríguez-Balderrama I, et al. Efficacy and safety of ultrasound-guided internal jugular vein catheterization in low birth weight newborn. J Pediatr Surg. 2016;51:1700-3.

105. Nardi N, Wodey E, Laviolle B, De La Brière F, Delahaye S, Engrand C, et al. Effectiveness and complications of ultrasound-guided subclavian vein cannulation in children and neonates. Anaesth Crit Care Pain Med. 2016;35: 209-13.

106. Breschan C, Graf G, Jost R, Stettner H, Feigl G, Neuwersch S, et al. A retrospective analysis of the clinical effectiveness of supraclavicular, ultrasound-guided brachiocephalic vein cannulations in preterm infants. Anesthesiology. 2018;128:38-43.

107. Lausten-Thomsen U, Merchaoui Z, Dubois C, Eleni Dit Trolli S, Le Saché N, Mokhtari M, et al. Ultrasound-guided subclavian vein cannulation in low birth weight neonates. Pediatr Crit Care Med. 2017;18:172-5.

108. Lamperti M, Bodenham AR, Pittiruti M, Blaivas M, Augoustides JG, Elbarbary $M$, et al. International evidence-based recommendations on ultrasoundguided vascular access. Intensive Care Med. 2012;38:1105-17.

109. Merchaoui Z, Lausten-Thomsen U, Pierre F, Ben Laiba M, Le Saché N, Tissieres P. Supraclavicular approach to ultrasound-guided brachiocephalic vein cannulation in children and neonates. Front Pediatr. 2017;5:211.

110. Hind D, Calvert N, McWilliams R, Davidson A, Paisley S, Beverley C, et al. Ultrasonic locating devices for central venous cannulation: meta-analysis. BMJ. 2003;327:361

111. Pirotte T, Veyckemans F. Ultrasound-guided subclavian vein cannulation in infants and children: a novel approach. Br J Anaesth. 2007;98:509-14.

112. Byon H-J, Lee G-W, Lee J-H, Park Y-H, Kim H-S, Kim C-S, et al. Comparison between ultrasound-guided supraclavicular and infraclavicular approaches for subclavian venous catheterization in children-a randomized trial. $\mathrm{Br}$ J Anaesth. 2013;111:788-92.

113. Eldabaa AA, Elgebaly A, Elhafz A, Bassun A. Comparison of ultrasoundguided vs. anatomical landmark-guided cannulation of the femoral vein at the optimum position in infant. South Afr J Anaesth Analg. 2012;18:162-6.

114. Smit JM, Raadsen R, Blans MJ, Petjak M, Van de Ven PM, Tuinman PR. Bedside ultrasound to detect central venous catheter misplacement and associated iatrogenic complications: a systematic review and meta-analysis. Crit Care. 2018;22:65.

115. Ablordeppey EA, Drewry AM, Beyer AB, Theodoro DL, Fowler SA, Fuller BM, et al. Diagnostic accuracy of central venous catheter confirmation by bedside ultrasound versus chest radiography in critically ill patients: a systematic review and meta-analysis. Crit Care Med. 2017;45:715-24.

116. Aouad MT, Kanazi GE, Abdallah FW, Moukaddem FH, Turbay MJ, Obeid MY, et al. Femoral vein cannulation performed by residents: a comparison between ultrasound-guided and landmark technique in infants and children undergoing cardiac surgery. Anesth Analg. 2010;111:724-8. 
117. Siddik-Sayyid SM, Aouad MT, Ibrahim MH, Taha SK, Nawfal MF, Tfaili YJ, et al. Femoral arterial cannulation performed by residents: a comparison between ultrasound-guided and palpation technique in infants and children undergoing cardiac surgery. Paediatr Anaesth. 2016;26:823-30

118. Gu W-J, Tie H-T, Liu J-C, Zeng X-T. Efficacy of ultrasound-guided radial artery catheterization: a systematic review and meta-analysis of randomized controlled trials. Crit Care. 2014;18:R93.

119. de Carvalho Onofre PS, da Luz Gonçalves Pedreira M, Peterlini MAS. Placement of peripherally inserted central catheters in children guided by ultrasound: a prospective randomized, and controlled trial. Pediatr Crit Care Med. 2012;13:e282-7.

120. Li Z, Chen L. Comparison of ultrasound-guided modified Seldinger technique versus blind puncture for peripherally inserted central catheter: a meta-analysis of randomized controlled trials. Crit Care. 2015; 19:64.

121. Alonso-Quintela P, Oulego-Erroz I, Rodriguez-Blanco S, Muñiz-Fontan M, Lapeña-López-de Armentia S, Rodriguez-Nuñez A. Location of the central venous catheter tip with bedside ultrasound in young children: can we eliminate the need for chest radiography? Pediatr Crit Care Med. 2015;16: e340-5.

122. Simanovsky N, Ofek-Shlomai N, Rozovsky K, Ergaz-Shaltiel Z, Hiller N, Bar-Oz B. Umbilical venous catheter position: evaluation by ultrasound. Eur Radiol. 2011;21:1882-6.

123. Katheria AC, Fleming SE, Kim JH. A randomized controlled trial of ultrasound-guided peripherally inserted central catheters compared with standard radiograph in neonates. J Perinatol. 2013;33:791-4.

124. Nguyen J. Ultrasonography for central catheter placement in the neonatal intensive care unit-a review of utility and practicality. Am J Perinatol. 2016; 33:525-30.

125. Kalanuria A, Nyquist PA, Armonda RA, Razumovsky A. Use of transcranial Doppler (TCD) ultrasound in the neurocritical care unit. Neurosurg Clin N Am. 2013;24:441-56.

126. Lau VI, Arntfield RT. Point-of-care transcranial Doppler by intensivists. Crit Ultrasound J. 2017;9:21.

127. Purkayastha S, Sorond F. Transcranial Doppler ultrasound: technique and application. Semin Neurol. 2012;32:411-20.

128. American College of Radiology (ACR), Society for Pediatric Radiology (SPR), Society of Radiologists in Ultrasound (SRU). AlUM practice guideline for the performance of a transcranial Doppler ultrasound examination for adults and children. J Ultrasound Med. 2012;31:1489-500.

129. Bellner J, Romner B, Reinstrup P, Kristiansson K-A, Ryding E, Brandt L. Transcranial Doppler sonography pulsatility index (PI) reflects intracranial pressure (ICP). Surg Neurol. 2004;62:45-51 discussion 51.

130. Bode $H$, Wais U. Age dependence of flow velocities in basal cerebral arteries. Arch Dis Child. 1988;63:606-11.

131. Rodriguez RA, Cornel G, Alghofaili F, Hutchison J, Nathan HJ. Transcranial Doppler during suspected brain death in children: potential limitation in patients with cardiac "shunt.". Pediatr Crit Care Med. 2002;3:153-7.

132. Vicenzini E, Pulitano P, Cicchetti R, Randi F, Papov P, Spadetta G, et al. Transcranial Doppler for brain death in infants: the role of the fontanelles. Eur Neurol. 2010;63:164-9.

133. Kluckow M, Evans N. Low superior vena cava flow and intraventricular haemorrhage in preterm infants. Arch Dis Child Fetal Neonatal Ed. 2000;82: F188-94.

134. Papile LA, Burstein J, Burstein R, Koffler H. Incidence and evolution of subependymal and intraventricular hemorrhage: a study of infants with birth weights less than 1,500 gm. J Pediatr. 1978;92:529-34.

135. Ducrocq X, Hassler W, Moritake K, Newell DW, von Reutern GM, Shiogai T, et al. Consensus opinion on diagnosis of cerebral circulatory arrest using Doppler-sonography: task force group on cerebral death of the Neurosonology Research Group of the World Federation of Neurology. J Neurol Sci. 1998;159:145-50.

136. O'Brien NF, Maa T, Yeates KO. The epidemiology of vasospasm in children with moderate-to-severe traumatic brain injury. Crit Care Med. 2015;43:67485.

137. Padayachy LC, Padayachy V, Galal U, Pollock T, Fieggen AG. The relationship between transorbital ultrasound measurement of the optic nerve sheath diameter (ONSD) and invasively measured ICP in children. : Part II: agerelated ONSD cut-off values and patency of the anterior Fontanelle. Childs Nerv Syst. 2016;32:1779-85.
138. Young AMH, Guilfoyle MR, Donnelly J, Scoffings D, Fernandes H, Garnett M, et al. Correlating optic nerve sheath diameter with opening intracranial pressure in pediatric traumatic brain injury. Pediatr Res. 2017:81:443-7.

139. Ballantyne J, Hollman AS, Hamilton R, Bradnam MS, Carachi R, Young DG, et al. Transorbital optic nerve sheath ultrasonography in normal children. Clin Radiol. 1999;54:740-2.

140. Malayeri AA, Bavarian S, Mehdizadeh M. Sonographic evaluation of optic nerve diameter in children with raised intracranial pressure. J Ultrasound Med. 2005;24:143-7.

141. Motuel J, Biette I, Srairi M, Mrozek S, Kurrek MM, Chaynes P, et al. Assessment of brain midline shift using sonography in neurosurgical ICU patients. Crit Care. 2014;18:676.

142. Llompart Pou JA, Abadal Centellas JM, Palmer Sans M, Pérez Bárcena J, Casares Vivas M, Homar Ramírez J, et al. Monitoring midline shift by transcranial color-coded sonography in traumatic brain injury. A comparison with cranial computerized tomography. Intensive Care Med. 2004;30:1672-5

143. Fernando SM, Tran A, Cheng W, Rochwerg B, Taljaard M, Kyeremanteng K, et al. Diagnosis of elevated intracranial pressure in critically ill adults: systematic review and meta-analysis. BMJ. 2019;366:14225.

144. Scalea TM, Rodriguez A, Chiu WC, Brenneman FD, Fallon WF, Kato K, et al. Focused assessment with Sonography for trauma (FAST): results from an international consensus conference. J Trauma. 1999;46:466-72.

145. Rozycki GS, Ochsner MG, Schmidt JA, Frankel HL, Davis TP, Wang D, et al. A prospective study of surgeon-performed ultrasound as the primary adjuvant modality for injured patient assessment. J Trauma. 1995;39:492-8 discussion 498-500.

146. Dammers D, El Moumni M, Hoogland II, Veeger N, Ter Avest E. Should we perform a FAST exam in haemodynamically stable patients presenting after blunt abdominal injury: a retrospective cohort study. Scand J Trauma Resusc Emerg Med. 2017;25:1

147. Tummers W, van Schuppen J, Langeveld H, Wilde J, Banderker E, van As A. Role of focused assessment with sonography for trauma as a screening tool for blunt abdominal trauma in young children after high energy trauma. $\mathrm{S}$ Afr J Surg. 2016;54:28-34.

148. Kameda T, Taniguchi N. Overview of point-of-care abdominal ultrasound in emergency and critical care. J Intensive Care. 2016;4:53.

149. McGahan JP, Richards J, Gillen M. The focused abdominal sonography for trauma scan: pearls and pitfalls. J Ultrasound Med. 2002;21:789-800.

150. Pereira BM, Pereira RG, Wise R, Sugrue G, Zakrison TL, Dorigatti $A E$, et al. The role of point-of-care ultrasound in intra-abdominal hypertension management. Anestezjologia Intensywna Terapia. 2017;49:373-81.

151. Akgür FM, Aktuğ T, Olguner M, Kovanlikaya A, Hakgüder G. Prospective study investigating routine usage of ultrasonography as the initial diagnostic modality for the evaluation of children sustaining blunt abdominal trauma. J Trauma. 1997;42:626-8.

152. Marin JR, Abo AM, Arroyo AC, Doniger SJ, Fischer JW, Rempell R, et al. Pediatric emergency medicine point-of-care ultrasound: summary of the evidence. Crit Ultrasound J. 2016:8:16.

153. Pon MS, Scudamore C, Harrison RC, Cooperberg PL. Ultrasound demonstration of radiographically obscure small bowel obstruction. AJR Am J Roentgenol. 1979;133:145-6.

154. Conlon TW, Himebauch AS, Fitzgerald JC, Chen AE, Dean AJ, Panebianco N, et al. Implementation of a pediatric critical care focused bedside ultrasound training program in a large academic PICU. Pediatr Crit Care Med. 2015;16: 219-26.

155. Nylund K, Maconi G, Hollerweger A, Ripolles T, Pallotta N, Higginson A, et al EFSUMB recommendations and guidelines for gastrointestinal ultrasound part 1: examination techniques and normal findings (long version). Ultraschall Med. 2017;38:e1-15.

156. Wale A, Pilcher J. Current role of ultrasound in small bowel imaging. Semin Ultrasound CT MR. 2016;37:301-12

157. Dorinzi N, Pagenhardt J, Sharon M, Robinson K, Setzer E, Denne N, et al. Immediate emergency department diagnosis of pyloric stenosis with pointof-care ultrasound. Clin Pract Cases Emerg Med. 2017;1:395-8.

158. Mercaldi CJ, Lanes SF. Ultrasound guidance decreases complications and improves the cost of care among patients undergoing thoracentesis and paracentesis. Chest. 2013;143:532-8.

159. Cuna AC, Reddy N, Robinson AL, Chan SS. Bowel ultrasound for predicting surgical management of necrotizing enterocolitis: a systematic review and meta-analysis. Pediatr Radiol. 2018;48:658-66. 
160. Silva CT, Daneman A, Navarro OM, Moore AM, Moineddin R, Gerstle JT, et al. Correlation of sonographic findings and outcome in necrotizing enterocolitis. Pediatr Radiol. 2007;37:274-82.

161. Sharma R, Hudak ML, Tepas JJ, Wludyka PS, Marvin WJ, Bradshaw JA, et al. Impact of gestational age on the clinical presentation and surgical outcome of necrotizing enterocolitis. J Perinatol. 2006;26:342-7.

162. Tam AL, Camberos A, Applebaum H. Surgical decision making in necrotizing enterocolitis and focal intestinal perforation: predictive value of radiologic findings. J Pediatr Surg. 2002;37:1688-91.

163. Epelman M, Daneman A, Navarro OM, Morag I, Moore AM, Kim JH, et al. Necrotizing enterocolitis: review of state-of-the-art imaging findings with pathologic correlation. RadioGraphics. 2007;27:285-305.

164. Aliev MM, Dekhqonboev AA, Yuldashev RZ. Advantages of abdominal ultrasound in the management of infants with necrotizing enterocolitis. Pediatr Surg Int. 2017;33:213-6.

165. Dördelmann M, Rau GA, Bartels D, Linke M, Derichs N, Behrens C, et al. Evaluation of portal venous gas detected by ultrasound examination for diagnosis of necrotising enterocolitis. Arch Dis Child Fetal Neonatal Ed. 2009;94:F183-7.

166. He Y, Zhong Y, Yu J, Cheng C, Wang Z, Li L. Ultrasonography and radiography findings predicted the need for surgery in patients with necrotising enterocolitis without pneumoperitoneum. Acta Paediatr. 2016; 105:e151-5.

167. van Druten J, Khashu M, Chan SS, Sharif S, Abdalla H. Abdominal ultrasound should become part of standard care for early diagnosis and management of necrotising enterocolitis: a narrative review. Arch Dis Child Fetal Neonatal Ed. 2019;104:F551-9.

168. Manzoni P, Martin GR, Sanchez Luna M, Mestrovic J, Simeoni U, Zimmermann $L$, et al. Pulse oximetry screening for critical congenital heart defects: a European consensus statement. Lancet Child Adolesc Health. 2017;1:88-90.

169. Martin GR, Beekman RH, Mikula EB, Fasules J, Garg LF, Kemper AR, et al. Implementing recommended screening for critical congenital heart disease. Pediatrics. 2013;132:e185-92.

\section{Publisher's Note}

Springer Nature remains neutral with regard to jurisdictional claims in published maps and institutional affiliations.

Ready to submit your research? Choose BMC and benefit from:

- fast, convenient online submission

- thorough peer review by experienced researchers in your field

- rapid publication on acceptance

- support for research data, including large and complex data types

- gold Open Access which fosters wider collaboration and increased citations

- maximum visibility for your research: over $100 \mathrm{M}$ website views per year

At $\mathrm{BMC}$, research is always in progress.

Learn more biomedcentral.com/submissions 